\title{
Malhação na sala de aula: o uso do exercício no ensino de línguas
}

Vilson J. Leffa

Universidade Católica de Pelotas - UCPEL

RESUMO: Este trabalho parte do pressuposto de que um problema sério no ensino de línguas é a divisão entre a teoria e a prática, que provocou uma separação aparentemente irreconciliável entre o cientista e o professor. $\mathrm{O}$ objetivo principal é examinar a possibilidade de uma aproximação entre os dois. Para isso, faz-se uma revisão do uso do exercício na sala de aula, tanto da perspectiva teórica, com ênfase na idéia do input generalizado, como da perspectiva prática, com ênfase na idéia do exercício localizado. Os dados, recolhidos de materiais didáticos propostos e implementados pelos teóricos do ensino de línguas, mostram que o cientista, quando assume o lugar do professor, apresenta um discurso mais próximo do professor do que do cientista. A conclusão é de que a aproximação entre a teoria e a prática é possível se o cientista e o professor formarem uma comunidade única para a troca de idéias e de experiências.

PALAVRAS-CHAVE: Hipótese do Input; Instrução de Processamento; Pensamento Teórico; Pensamento Prático.

ABSTRACT: This paper is based on the assumption that a serious problem in language teaching is the division between theory and practice, which led to an apparently irreconcilable separation between the scientist and the teacher. Its main objective is to examine the possibility of an approximation between them. For that purpose, I make a review on the use of exercises in the classroom, not only from a theoretical perspective, with an emphasis on the idea of generalized input, but also from a practical perspective, with an emphasis on the idea of localized drills. The data, collected from teaching materials that were proposed and implemented by language teaching theoreticians, show that the scientist, when talking from a teacher's position, presents a discourse that is closer to the teacher than to the scientist. The conclusion is that the approximation between theory and practice is possible if the scientist and the teacher join a community where ideas and experiences can be exchanged.

KEYWORDS: Input hypothesis; Processing Instruction; Theoretical Thinking; Practical Thinking.

\section{Introdução}

A idéia de que se aprende a fazer fazendo é provavelmente tão antiga quanto a própria humanidade; deve ter surgido quando o primeiro homem 
lascou a primeira pedra e se transformou em mestre para que outros aprendessem com ele. Esses primeiros aprendizes aprendiam a lascar sem ouvir explicaçóes, ler manuais ou usar simulações, mas lascando pedras de verdade ao lado do mestre. $\mathrm{O}$ uso de material autêntico, em situações autênticas de prática está presente em todas as épocas e em todas as culturas, principalmente em situações informais de ensino: é o caso, por exemplo, do aprendiz de alfaiate, na cultura Vai e Gola da Libéria, que aprende a costurar costurando ao lado do mestre (GOODY, 1989); é o caso da aprendiz de parteira, na cultura maia, que aprende a fazer partos com sua mãe (JORDAN, 1989).

É com a criação da escola, e a conseqüente formalização do ensino, que ocorreu a substituição do material autêntico pelo material simulado, introduzindo-se aí o manual, o livro didático e a prática do exercício. Há um afastamento entre a atividade realizada pelo aprendiz e o produto final esperado dessa atividade, ocorrendo, com esse afastamento, o risco da alienação do aprendiz. O objetivo final da atividade realizada na sala de aula nem sempre está claro para o aluno, e muitas vezes nem para o professor. $\mathrm{O}$ aluno preenche uma folha de atividades e a entrega para o professor preocupado apenas com o resultado da avaliação, incapaz de estabelecer uma relação entre o que fez e a aprendizagem final pretendida. O professor, por sua vez, avalia o exercício que ele mesmo propôs, dentro dos limites do próprio exercício, sem a preocupação de olhar além. Constrói-se um mundo artificial, feito de necessidades, regras e obrigações que só existem dentro da escola e que, no máximo, podem servir para preparar o aluno para a etapa seguinte da progressão educacional. No ensino médio, tenta-se preparar o aluno para o vestibular; na graduação, muitas das disciplinas oferecidas são pré-requisitos de outras, além de programas de iniciação científica que visam explicitamente preparar o aluno para o mestrado e no mestrado para o doutorado e, assim, sucessivamente, até chegar ao pós-doutorado, que em alguns casos é também uma preparação para outro pós-doutorado. Há muitas pessoas que nunca saem da escola, evoluindo apenas de aluno para professor. É de se perguntar até que ponto essas pessoas estariam realmente preparadas para ensinar para a vida. Por mais que se repita que aprendemos para a vida e não para a escola, poucos são os professores que têm experiência de vida fora da sala de aula. $\mathrm{O}$ risco, nesse caso, é que essa falta de experiência com o que acontece no mundo real, tornaos incapazes de preparar seus alunos para o que não conhecem. O resultado dessa longa estadia dentro dos muros da universidade é o distanciamento entre a teoria e a prática, levando à hipertrofia do discurso, que se agiganta como 
representação construída da realidade e a atrofia da prática, que se desqualifica como uma visão equivocada dessa realidade. A formalização do ensino e a crescente substituição do material autêntico pelo simulado acabaram gerando um abismo entre a teoria e a prática.

Criam-se, assim, dois tipos de pensamento, que podemos definir como pensamento teórico, aquele construído dentro dos muros da academia, e o pensamento prático, construído no embate com a realidade do dia-a-dia. Esses dois tipos de pensamento estão relacionados a dois tipos de professores: os professores e os professores dos professores. O professor está mergulhado no contexto imediato; não tem uma idéia clara da história e de como as coisas evoluem, mas conhece a realidade de perto pelo que vivencia através dos cinco sentidos: pelo que vê, ouve, cheira, apalpa e prova. É o domínio do pensamento sensível ou prático. O professor dos professores, ao contrário, olha a realidade de longe, abstraída de seu contexto imediato. O que vê é uma representação da realidade, geralmente relatada por terceiros, incluindo orientandos e outros professores. É o domínio do pensamento teórico. Não vê o detalhe, mas tem uma visão panorâmica que mostra o contexto maior, incluindo o entorno espacial e a história, com seus avanços e recuos.

Historicamente parece haver uma divisão de tarefas entre quem usa o pensamento teórico e quem usa o pensamento prático. Quem usa o pensamento teórico trabalha com a mente e ocupa o topo da pirâmide trabalhista, exercendo cargos gerenciais ou de chefia; no mundo da educação, o exemplo típico é o do pesquisador. Já quem usa o pensamento prático está na base da pirâmide trabalhista; seja o marceneiro na sua bancada de trabalho, o soldado na trincheira e, na área da educação, o professor do ensino básico na sala de aula. Os dois tipos de pensamento implicam responsabilidades diferentes, como veremos mais adiante; a responsabilidade do cientista é de natureza metodológica, com ênfase no processo; a do professor é de natureza prática, com ênfase nos resultados.

O objetivo deste trabalho é mostrar o abismo que separa o pensamento teórico do prático e tentar estabelecer a fusão que se faz necessária entre ambos. Para propor essa tentativa de fusão, usa-se como exemplo a proposta do exercício na sala de aula de língua estrangeira ou segunda língua (L2, doravante), vista como uma das áreas em que mais se destacam as diferenças entre a teoria, que induz a ruptura, e a prática, que tenta preservar a continuidade. Argumenta-se que o principal motivo que leva à ruptura ou à continuidade é a consciência da responsabilidade social, extremamente diferenciada à medida que envolve o cientista ou o professor. 


\section{Abismo entre teoria e prática}

De modo geral, o emprego do exercício na aprendizagem de línguas, em qualquer um dos grandes domínios - psicomotor, cognitivo ou afetivo - varia bastante entre a teoria e a prática. Na prática, privilegia-se a fragmentação: busca-se discriminar e classificar os inúmeros comportamentos que se deseja desenvolver nos alunos, abrindo espaço para que se proponha uma infinidade de exercícios, cada vez mais especializados para atender a objetivos cada vez mais específicos. O aluno é visto como uma garrafa de gargalo estreito, de modo que a aprendizagem só ocorre se o conteúdo for colocado aos poucos, a contagotas. A principal crítica teórica a essa abordagem fragmentada, privilegiada pelo pensamento prático, é de que a fragmentação dos comportamentos em blocos mínimos pode levar a uma granularização dos exercícios, provocando anomalias que hipertrofiam determinadas partes, atrofiam outras e não possibilitam o desenvolvimento harmônico do corpo da língua. Os segmentos aprendidos pelo aluno ficam isolados um do outro, como competências específicas, incapazes de se integrar numa competência lingüística maior. Os exemplos da história da aprendizagem de línguas são bastante comuns e têm sido repetidos ad nauseam: o aluno decora palavras, mas não sabe produzir uma frase; ou produz frases feitas, mas não sabe se comunicar na língua em contextos de uso autêntico.

$\mathrm{Na}$ teoria, por outro lado, privilegia-se o holismo. O aluno é visto como um todo indivisível, sem possibilidade de separação entre os domínios psicomotor, cognitivo ou afetivo. Essa visão do todo, muitas vezes, extrapola o próprio indivíduo e abrange a coletividade em que está inserido. O conteúdo não é algo que é introduzido para dentro do aluno pelo professor, mas algo que o aluno constrói na sua interação com os outros. Tudo interage com tudo. Dentro do aluno, o domínio psicomotor interage com o domínio cognitivo, esse com o afetivo e, fechando o círculo, o afetivo com o psicomotor. $\mathrm{O}$ aluno como sujeito, por outro lado, interage com os outros alunos, com os demais membros da comunidade e com o próprio mundo. Tudo está contextualizado e interligado. O holismo, por ser uma proposta do pensamento teórico, e pelo prestígio que impõe, não chega a ser criticado pelos professores. A prática não critica a teoria; ignora-a.

A tendência da prática é preservar a continuidade, mantendo as coisas como elas são e estão, seguindo um movimento a-histórico, em linha reta. Já a teoria é inquieta e movimenta-se bastante, às vezes como um pêndulo, indo de um lado para outro, às vezes como uma espiral, evoluindo à medida que 
balança. No movimento do pêndulo, há ocasiōes em que a teoria está bem próxima da prática. Foi o que aconteceu, por exemplo, durante o período áudio-lingual, na década de sessenta: o estruturalismo bloomfildiano, da teoria lingüística, e o behaviorismo skinneriano, da Psicologia, com ênfase na repetição e imitação de modelos frasais, os "pattern drills", estavam muito próximos do que sempre se fez na sala de aula, com os alunos repetindo em coro o que era dito pelo professor. Já em outros momentos, quando se pregava a ênfase na comunicação e no uso de materiais autênticos, a distância era maior. A distância máxima entre teoria e prática parece ter sido alcançada com a proposta teórica de que se aprende uma língua por exposição ao input lingüístico. A idéia de que se aprende uma L2 incidentalmente, do mesmo modo como adquirimos a língua materna, parece incompatível com o ensino formal da sala de aula. A aproximação entre o pensamento teórico e o prático, quando ocorre, é sempre por iniciativa da teoria, que vai ao encontro da prática. A prática, por sua vez, permanece inflexível, sem desvio de rota, refratária a qualquer tentativa de mudança.

Uma das áreas de maior conflito entre a teoria e a prática está no uso do exercício na sala de aula. Para a prática, o conteúdo a ser ensinado, para ser apresentado ao aluno, deve ser fragmentado em segmentos menores, às vezes até o nível do fonema. $\mathrm{O}$ aluno que estuda inglês, por exemplo, deve saber que as palavras "bed" e "bad" distinguem-se uma da outra pela vogal, normalmente indistinguível para falantes da língua portuguesa. Para corrigir esse problema o aluno deve aprender não só a ouvir a diferença entre os fonemas, mas também o produzir um e outro. Isso é feito através de exercícios, geralmente pela escuta e repetição de pares mínimos ("bed-bad", "said-sad", etc.). O uso do exercício para desenvolvimento dos automatismos, que acontece no nível fonológico, acontece também no nível lexical, sintático e pragmático.

Depois de selecionados e isolados para a prática dos alunos, os itens são ordenados de alguma forma, geralmente pelos critérios de facilidade de aprendizagem e de utilidade, usando-se os dois quando possível. No caso da língua inglesa, desde tempos imemoriais, o primeiro item tem sido o verbo "to be"; raros são, por exemplo, os livros didáticos que não comecem por aí. Finalmente para a prática do aluno, privilegia-se a repetição de segmentos lingüísticos e sua manipulação: conjugação (I’m Brazilian; he’s American), negação (He's not American; he's English), interrogação (Are you French?), etc. Os processos de fragmentação, ordenação, repetição e manipulação são elementos importantes do pensamento prático e que ajudam a compor o 
grande sistema do ensino de línguas: Seleção, Ordenamento, Prática e Avaliação (SOPA).

\section{A teoria na teoria}

Para o pensamento teórico, as idéias de fragmentação, ordenação, repetição e manipulação da língua são todas vistas como equivocadas. Não se aprende uma língua isolando segmentos, ordenando as partes em seqüência e principalmente não se aprende uma língua fazendo exercícios de manipulação desses fragmentos em sala de aula. $\mathrm{O}$ uso do exercício é visto não só como inútil, mas até como prejudicial; em vez de facilitar acaba atrapalhando a aprendizagem da língua.

Vários autores têm condenado o uso do exercício, associando-o a abordagens anacrônicas que colocam o professor no centro do processo de aprendizagem, como emissor do conhecimento a ser absorvido pelo aluno, provendo o modelo a ser imitado e controlando a seqüência do conteúdo (NUNAN, 1992, p. 195). O uso do exercício não tem nem embasamento teórico para se sustentar nem utilidade prática que justifique seu uso (STERN, 1991, p. 465). Sua prática acaba sobrevivendo apenas porque o exercício é imposto ao aluno, que, por sua vez, não vê qualquer utilidade no seu emprego.

A crítica mais forte contra o uso do exercício veio de Bill VanPatten, num artigo publicado com Wynne Wong (WONG; VANPATTEN, 2003) sob o título sugestivo de "The evidence is IN: Drills are OUT" (maiúsculas no original), que poderia ser livremente traduzido como "A evidência chegou: chega de drills".

Pela relevância desse artigo à argumentação feita neste trabalho, faz-se necessária uma revisão mais aprofundada das idéias ali expostas. O objetivo do artigo de Wong e VanPatten é avaliar se o uso de drills contribui para a aquisição da língua ou mesmo para melhorar o desempenho do aluno ao longo do tempo. A resposta, que já se pode adiantar, é não.

Para chegar a essa conclusão, os autores fazem uma longa revisão de todos os teóricos da área que de um modo ou outro defenderam o uso de drills na aprendizagem da L2 e vão desqualificando um a um os argumentos apresentados por todos eles, incluindo aí Brooks (1960), Paulston (1976), Littlewood (1980), Rivers (1981), Hammerly (1991), Stevick (1996), Nunan (1999) e Omaggio Hadley (2001), entre outros. Não interessa que Paulston, por exemplo, tenha classificado os drills em mecânicos, significativos e 
comunicativos ou que Omaggio Hadley os divida em descontextualizados e contextualizados. A conclusão é sempre a mesma: "drills are out" ("chega de drills").

Como o aluno adquire a L2 então? A resposta, segundo VanPatten, é clara: por exposição ao input lingüístico que o rodeia. "O desenvolvimento da língua não depende da prática que o aprendiz faz com a língua, mas de sua exposição ao input" (WONG; VANPATTEN, 2003, p. 404). Essa exposição não pode ser passiva: o aluno tem que ser levado a processar o input. Esse input, como já defendia Krashen, tem que ser compreensível: adquire-se uma L2, primeiramente compreendendo a língua; só depois, muito depois, é que se deve produzi-la. O problema maior do drill, segundo Wong e VanPatten, é que justamente leva o aluno a falar e escrever antes que esteja preparado para isso.

\section{Desconstuindo o drill}

Um dos problemas que têm contribuído para a separação indesejável entre a teoria e prática é o significado das palavras exercício e drill. É preciso ficar clara a diferença entre uma e outra. Drill tem uma conotação extremamente mecanicista, associada não só ao treinamento feito com soldados, mas até com instrumentos de tortura, incluindo, por exemplo, a broca usada pelo dentista ("drill" em inglês). Enquanto o exercício pode ser feito para manter a forma física, preservar a saúde e outras atividades de caráter positivo, o drill é reservado para atividades geralmente vistas como enfadonhas e tem uma conotação claramente negativa. Numa escala do mais ao menos prazeroso, o significado da palavra exercício tem uma amplitude maior do que a palavra drill, que decididamente se encolhe para o lado mais desagradável. No ensino de L2, o uso da palavra drill está atualmente associado à idéia de exercício mecânico e repetitivo, com ênfase na forma.

Isso significa que quando alguém, usando a língua inglesa, quer desqualificar a atividade que é feita pelo professor no ensino da L2, vai preferir o uso da palavra drill em vez de exercício. É o que fazem Wong e VanPatten em seu artigo; tudo é drill para esses autores.

Mesmo em inglês a palavra $d r i l l$, de clara conotação mecanicista, tem sido às vezes usada no sentido de uma atividade interativa, com ênfase na negociação de sentido. Retomando aqui o texto clássico de Paulston (1976), vemos que ela atribui três níveis de uso para a palavra drill na sala de aula: (1) drill automático, (2) drill significativo e (3) drill comunicativo.

$\mathrm{O}$ drill automático é aquele em que o professor tem o controle total da resposta a ser dada pelo aluno, partindo de um modelo estabelecido que admite 
apenas uma única resposta como certa, de acordo com a deixa. Exemplo de drill automático:

Modelo: I like movies.

Deixa: $\mathrm{He}$

Resposta: He likes movies.

Deixa: We

Resposta: We like movies.

(...)

O drill automático, como o próprio nome indica, deve levar, pela constante repetição e manipulação, ao automatismo no uso dos padróes frasais da língua. Paulston defende que, à medida que a língua envolve a formação de hábitos, a repetição dos padrões frasais com o uso do drill automático é uma etapa necessária para sua aprendizagem.

$\mathrm{O}$ drill significativo envolve um conteúdo semântico que precisa ser compreendido pelo aluno para chegar à resposta certa. A deixa pode ser uma palavra, uma figura, um flash card ou mesmo uma combinação de ambos. Às vezes envolve também algum tipo de instrução inicial (ex.: responda com frases completas). Exemplo de drill significativo, usando os objetos dos próprios alunos:

Modelo: Peter's shirt is black.

Deixa: What color is Maria's blouse?

Resposta: Maria's blouse is pink.

Deixa: What color is Jane's pen?

Resposta: Jane's pen is blue.

No drill significativo, o aluno precisa associar o significante ao significado, estabelecendo a relação correta entre o que está sendo expresso, tanto pronunciado como escrito, e o referente no mundo real. A resposta, por exemplo, estará errada, se o aluno responder que a caneta da Jane é vermelha, quando na realidade é azul, mesmo que o aluno tenha usado uma estrutura gramatical correta. Pode-se dizer, portanto, que o drill significativo envolve também o aspecto semântico.

Finalmente, no drill comunicativo, o aluno é solicitado a dar informações que o interlocutor não conhece. Não existe mais um modelo a ser seguido nem padrões frasais determinados; o diálogo é livre e a resposta pode ser totalmente imprevisível. Imaginando-se, por exemplo, uma pergunta como "What did you do last night?", não é possível prever o que o aluno possa responder. O professor pode até esperar que o aluno responda com um verbo 
no passado, mas rigorosamente terá que aceitar qualquer resposta - desde que gramaticalmente correta. A ironia do drill comunicativo na aula de L2 é que o professor estará mais atento à forma do que ao conteúdo. Quanto ao conteúdo, o aluno é livre para dizer o que quiser, podendo até mentir à vontade. Não pode é titubear quanto à forma; aí será corrigido pelo professor. O que deveria ser, portanto, uma interação comunicativa não passa de um mero exercício estrutural, avaliado em termos puramente gramaticais.

Wong e VanPatten vêem pouca ou nenhuma diferença entre os três tipos de drill. Como o objetivo, basicamente, é a prática dos padrões frasais, não há nem necessidade, segundo eles, de usar mais de um tipo de exercício para fazer o que poderia ser feito com um.

\section{A teoria na prática: o paradoxo}

Alguns autores do pensamento teórico produzem também algumas propostas didáticas, geralmente livros-texto, para uso de professores e alunos na sala de aula. No Brasil, por exemplo, temos Luiz Paulo da Moita Lopes, autor da série didática Read, Read, Read (MOITA LOPES, 1999). Na Inglaterra, temos, entre tantos outros, os nomes de Jack Richards (RICHARDS; HULL; PROCTOR, 2005), David Nunan (NUNAN, 2001), Michael McCarthy (McCARTHY; McCARTEN; SANDIFORD, 2005), Willis (WILLIS; WILLIS, 1988). Todos são autores que compartilham tanto do pensamento teórico, produzindo obras de reflexão para professores, como do pensamento prático, produzindo livros didáticos para uso dos alunos. Embora nem todos tenham se pronunciado explicitamente contra o uso de drills, quando estão do lado da teoria, todos recorreram fartamente ao uso do exercício, quando passam para o lado da prática, ao fazerem suas propostas didáticas.

Há exercícios de todos os tipos, incluindo preenchimento de lacunas, pergunta-resposta, manipulação de sentenças, múltipla escolha, falsoverdadeiro, etc. Veja-se, a título de ilustração, uma breve amostra de três dos autores citados:

Moita Lopes, em seu livro didático Read, read, read, no primeiro volume, destinado à quinta série do ensino fundamental:

Copie e complete no caderno as frases abaixo:

..... is the first day of the week.

..... is the second day of the week. 
Tuesday is the ..... day of the week.

Wednesday is the ..... day of the week.

(...)

(MOITA LOPES, 1999, p. 21).

Richards, com dois outros autores, no primeiro volume da conhecida série Interchange, em terceira edição, destinada a adultos e jovens adultos:

Complete these sentences. Then tell a partner about yourself.

1. My name ..... David Garza. I'm from Mexico. ..... family is in Mexico City. My brother ..... a university student. ..... name is Carlos. (...)

(RICHARDS; HULL; PROCTOR, 2005, p.3).

Nunan, da série Expressions 2: Meaningful English communication, com um exercício de reconhecimento de palavras (Circular a palavra que é diferente das outros):

Circle the one that is different.

1. straight curly short glasses

2. mustache middle-aged earrings glasses

3. short average-height young tall

(...)

(NUNAN, 2001, Unit 3).

O caso mais interessante ainda é o de Wong e VanPatten (2003), considerando principalmente a truculência que usaram para induzir o leitor a rejeitar qualquer proposta baseada na prática de exercícios. Começa pelo título que deram ao artigo ("Evidence is IN: drills are OUT") e continua pelo aporte teórico, fundamentado na idéia de que aprender uma L2 não depende da prática de exercícios, mas de exposição ao input. $\mathrm{O}$ interesse maior pelo trabalho de Wong e VanPatten, no entanto, está no fato de que não ficaram apenas na teoria, mas ofereceram também uma proposta prática de implementação.

Para essa proposta prática, fazem antes uma resenha detalhada não só da importância do input na aquisição da L2, mas também das pesquisas feitas em sala de aula que desqualificam o uso dos drills na aprendizagem. A conclusão em relação aos drills é de que eles, além de não serem necessários, atrapalham a aquisição da língua. Em seu lugar, os autores oferecem uma proposta alternativa, que chamam de "Processing Instruction" (Instrução de Processamento), na qual os aprendizes são explicitamente levados a processar determinadas estruturas para chegar ao seu significado. $\mathrm{O}$ exemplo a seguir mostra uma 
atividade proposta pelos autores para o ensino da estrutura causativa da língua francesa, que se caracteriza por frases do tipo "Jean fait promener le chien à Marie" (Literalmente: "João mandou passear o cachorro a Maria", ou seja, "João mandou Maria passear com o cachorro"). Como essa estrutura, pela sua ordem inusitada, apresenta dificuldades de compreensão para falantes nativos de algumas línguas, incluindo aí falantes do inglês e do português, faz-se necessário um tipo de atividade que induza o aluno a perceber essa diferença e o leve a processar adequadamente a estrutura. Como é feito isso? Através do que os autores chamam de input estruturado, como é mostrado a seguir:

[Instrução] Nesta atividade você vai comparar e contrastar como se pede que uma criança ou um cão faça alguma coisa. Para cada item, indique se ele se refere a uma criança (à l'enfant), ao cão (au chien) ou possivelmente aos dois (à tous les deux):

Un adulte..

1. fait chercher l'os à/au

2. fait faire la vaisselle à/au

3. fait manger à une certaine heure à/au

4. fait jouer dehors à/au

5. fait se baigner à/au

6. fait dormir au plancher à/au

7. fait boire du lait à/au

Todos na aula concordam?

Para os autores, a atividade proposta acima não é um drill porque os alunos não produzem a estrutura na língua-alvo, ou seja, devem apenas compreender a frase, processando-a, mas não produzir a estrutura. Percebe-se, assim, que Wong e VanPetten retomam a proposta de Krashen (1985) e demais proponentes que defendem a idéia da compreensão primeiro, produção depois (WINITZ, 1981; KRASHEN; TERRELL, 1983).

A proposta de exercício com base no input estruturado, apresentada por Wong e VanPatten, apresenta duas características que devem ser destacadas:

- Frases descontextualizadas. Ao contrário dos exercícios apresentados nos livros didáticos analisados (vejam-se os exemplos acima), em que se nota a preocupação de relacionar as frases, ou mesmo palavras, a um tema específico (dias da semana, família, aparência física), os exemplos de Wong e VanPatten possuem entre si um vínculo apenas estrutural. 
- Ênfase na compreensão. A necessidade de compreender o conteúdo da frase para a execução do exercício proposto por Wong e VanPatten, e apresentada pelos autores como uma novidade, é na verdade uma prática generalizada nas atividades de sala de aula, como se pode também perceber nos três livros analisados acima.

A diferença maior não está entre os exercícios propostos por Wong e VanPatten e os exercícios encontrados nos livros didáticos usados pelos professores. São até bastante semelhantes. A diferença maior está entre o que propõem teoricamente (o fim do exercício) e o que fazem na prática (a defesa do exercício).

Um exame atento do artigo de Wong e VanPatten mostra que há nele um paradoxo entre a teoria e a prática. $\mathrm{Na}$ teoria, defendem a idéia de que se aprende a L2, não pela prática do exercício (“drills are out”), mas pela exposição ao input, partindo da teoria de Krashen (1985). Na prática, porém, o que propõem é justamente o uso do exercício com frases que nem chegam a ser contextualizadas, contrariando, inclusive, o que defende Krashen, que tem valorizado a importância do contexto na aquisição da L2 (KRASHEN, 1981; KRASHEN, 2004).

Obviamente não faltam teorias para explicar o paradoxo, incluindo a questão do descentramento do sujeito (ex.: HALL, 2003) ou da heterogeneidade (ex.: AUTHIER-REVUZ, 1990). O lugar de onde se fala afeta o que se diz. Quando Wong e VanPatten falam do lugar teórico adotam a postura do cientista e alinham-se pela hipótese do input (KRASHEN, 1985). Já quando falam do lugar da prática adotam a postura do professor e alinham-se pelo que deve ser feito na frente dos alunos.

Parece haver aqui uma questão de responsabilidade, a partir da conseqüência da ação de cada um, o que também não pode ser ignorado. $\mathrm{O}$ cientista e o professor têm responsabilidades diferentes. O cientista é responsável, única e exclusivamente, perante a comunidade à qual pertence (KUHN, 1962). O professor, por outro lado, é responsável por uma comunidade maior, com várias subcomunidades: inclui os alunos, a escola em que trabalha (com seu pessoal administrativo e colegas), os pais dos alunos, etc. O cientista, quando erra, pode refazer a hipótese. O professor, quando erra, perde o emprego. O pensamento prático não tolera o erro (LAVE; WENGER, 1991).

Em termos de mudança, o cientista e o professor estão em pólos opostos. O cientista está mais comprometido com a história. Sua responsabilidade 
perante a comunidade a que pertence implica a preocupação com o desenvolvimento da área que investiga. Tem o privilégio de poder se arriscar mais e, com isso, tem mais possibilidade de mudar a história. Ciência é ruptura e ninguém ao longo da história tem produzido tantas mudanças como o cientista. Já o professor, por não poder se arriscar tanto, tende a optar pela continuidade, evitando a ruptura com o que está estabelecido.

O ideal seria não acusar um ou outro de irresponsabilidade, mas tentar unir os dois tipos de compromissos, tanto o compromisso pela mudança, por parte do cientista, como o compromisso pelos resultados, por parte do professor. Fundem-se, desse modo, o pensamento prático com o teórico. É o que se propõe a seguir.

\section{Tentativa de fusão}

O objetivo deste trabalho não é separar a teoria da prática, nem contribuir para fazer uma prevalecer sobre a outra. Parte-se do pressuposto de que seria tão errado argumentar que a teoria deveria predominar sobre a prática como é errado achar que a prática é mais importante do que a teoria. O objetivo maior é tentar mostrar que uma precisa da outra. A teoria pode proporcionar a visão do todo, à medida que contextualiza qualquer evento em seu lugar espacial e histórico, sem perder de vista, portanto, o que está ao lado e o que já aconteceu antes; o que é tão importante como a visão da parte, proporcionada pela prática, capaz de mostrar em profundidade o que se faz a cada momento.

A conhecida metáfora dos quatro cegos apalpando o elefante pode ser usada a guisa de ilustração: o primeiro cego toca a perna e diz "é uma árvore"; o segundo toca a cauda e diz "é um chicote"; o terceiro toca a tromba e diz "é um tubo"; finalmente o quarto toca a barriga e diz "é um navio". Só quem vê o elefante como um todo, preferencialmente à distância, sabe muito bem que o elefante não é nem uma árvore, nem um chicote, nem um tubo e nem um navio. Mas ele também deixa de ser um elefante se não possuir essas partes; um elefante sem tromba já será um outro animal. Da mesma maneira, o professor, mergulhado no seu dia-a-dia, pode ver o ensino da L2 como um exercício de manipulação de frases. Já quem olha de longe sabe que aprender uma língua não é só completar frases, não é só traduzir, não é só imitar um modelo, não é só fazer exercícios. Mas também deixa de ser aprendizagem se não houver uma atividade que envolva os alunos. Não existe o todo sem as partes como não existe a parte sem o todo. 
A metáfora do elefante sugere que não se pode dar ao aluno um conjunto de frases isoladas e achar que está dando a língua. Mas também, por outro lado, não se pode pressupor que a aquisição da L2 pelo aluno dá-se sem conhecimento das partes, como se a língua fosse um bloco monolítico, indivisível. É a metáfora da lente fotográfica: o aluno adquire a língua por partes, uma depois da outra, como uma imagem que passa por uma lente, ponto a ponto, que se ampliam momentaneamente para depois projetar no fundo da câmera, a imagem completa e luminosa. A língua como um todo só é adquirida se passar por esse processo de fragmentação, para que possa penetrar pelas passagens estreitas dos sentidos (principalmente a audição e visão), e ser posteriormente recomposta dentro da mente do aluno. A língua não entra na mente como um bloco monolítico; entra desmontada em fragmentos, como aqueles navios de brinquedo que são introduzidos peça a peça e remontados dentro de garrafas.

O que é então aprender uma língua numa proposta que considere tanto a prática como a teoria? É tentar unir a prática do professor em desmontar o todo, construindo a trilha do passo a passo, com a teoria do cientista, que apresenta o mapa geral da língua. $\mathrm{O}$ aluno precisa tanto da trilha como do mapa para não se desorientar.

Não é fácil fazer essa fusão entre a teoria e a prática. São várias as dificuldades encontradas. Algumas teorias são refratárias a qualquer prática do professor, e algumas práticas são totalmente refratárias a qualquer teoria. Há cientistas que são incapazes de explicar sua teoria fora de seu pequeno círculo de investigação, como também há professores que rejeitam qualquer proposta teórica que mexa em sua prática. Há uma rejeição mútua que às vezes cria barreiras intransponíveis.

O primeiro passo na tentativa de uma fusão é decidir por onde começar, se pela teoria ou pela prática. Parece mais aconselhável começar pela teoria, considerando, entre outros aspectos, o prestígio maior que a teoria exerce em relação à prática. O segundo passo, depois de optar por onde começar, é decidir por uma teoria que tenha, ao mesmo tempo, prestígio na comunidade científica e que não seja refratária à prática. A questão do prestígio vai sempre variar de uma época para outra, à medida que mudam os paradigmas (estruturalismo, cognitivismo, construtivismo, construtivismo social, etc.), o que sugere um cuidado especial para não se optar por um paradigma teoricamente superado, ainda que possa parecer o mais próximo da prática. O que se propõe aqui para tratar da questão do uso do exercício na aprendizagem de línguas está baseado 
nas idéias de Vygotsky, envolvendo o papel da consciência e da comunidade. Ao exercer qualquer atividade, incluindo até um drill, é necessário, em primeiro lugar, que se tenha consciência do objetivo a que se quer chegar, estabelecendo assim uma relação clara entre o que se faz e o objetivo pretendido; em segundo lugar, é também necessário que se esteja numa comunidade que compartilha desse objetivo, a fim de que se possam trocar experiências e idéias, ajudandose mutuamente.

Parte-se, portanto, de um sujeito ativo e consciente que tem uma intencionalidade, possivelmente construída na interação com a comunidade em que vive, num movimento que vai de fora para dentro. Essa consciência tem níveis de controle, desde atividades que exigem a atenção do sujeito, até operações que estão abaixo do nível da consciência, por já estarem automatizadas. A aquisição da proficiência na L2 pressupõe uma transferência constante da atividade consciente para o nível dos automatismos por meio da prática e do exercício. $\mathrm{O}$ papel do exercício é importante porque à medida que desenvolve o automatismo das operaçoos possibilita a fluência na língua. Enquanto a atenção é exigente no uso dos recursos cognitivos, normalmente permitindo apenas o processamento serial, em que uma operação é realizada de cada vez, o processamento automático pode ser realizado em paralelo, permitindo que várias operações sejam realizadas ao mesmo tempo e possibilitando, pela rapidez de processamento, a fluência na língua.

Esse sujeito ativo e consciente não está isolado no mundo, mas tipicamente vive e age dentro de diversas comunidades, incluindo aí, por exemplo, a comunidade do bairro em que vive, do time de futebol pelo qual torce, da empresa em que trabalha, da igreja a que possivelmente pertence, dos proprietários de uma determinada marca de automóvel, dos usuários de um determinado produto, dos fãs de uma banda, etc. Aprender uma L2 é tentar se inserir na comunidade dos aprendizes dessa língua. Essa comunidade terá regras que o aluno deverá conhecer e seguir (possivelmente horários de aula, mensalidades a serem pagas, provas e exercícios a serem realizados, etc.), divisão de trabalho com tarefas a serem cumpridas e responsabilidades a serem distribuídas (se o aluno estiver matriculado numa escola, por exemplo, haverá alguém responsável pela administração dos cursos, pela aquisição do material necessário para as aulas, pela elaboração dos horários, limpeza do prédio, etc.), objetivos que o aluno deverá compartilhar e artefatos típicos (livros, gravadores, vídeos, etc.), que viabilizarão a consecução dos objetivos estabelecidos.

$\mathrm{O}$ sucesso na aprendizagem de L2 dá-se à medida que alunos e professores compartilham dos mesmos objetivos, tendo ambos consciência 
clara do que se pretende com cada atividade realizada em sala de aula. $\mathrm{O}$ exercício é normalmente um processo de mediação para se chegar a um determinado objetivo. Se esse objetivo não for compartilhado e a relação entre a atividade e o objetivo não for clara, a aprendizagem não ocorre. No exemplo dado por Wong e VanPatten, em que se pretende que o aluno processe sintaticamente a frase "fait chercher l'os àlau..." para achar a resposta correta (que é "chien"), o aluno poderia, por exemplo, chegar à mesma resposta apenas pela associação da palavra "cão" com a palavra "osso", deturpando a finalidade do exercício, pretendida pelo professor. Se isso acontecesse não haveria aprendizagem. $\mathrm{O}$ exercício seria mais uma atividade inócua, totalmente improdutiva, gerando apenas o fracasso da aprendizagem.

Outras vezes há um desvio entre os objetivos do professor e os objetivos do aluno, ocultando conflitos que nem chegam à superfície. Uma atividade que deveria ser feita para desenvolver uma determinada competência lingüística pode ser feita pelo aluno apenas para melhorar a nota, agradar o professor ou, pior ainda, para aborrecê-lo. Às vezes o aluno até tem boa vontade e tenta executar a tarefa da melhor maneira possível, mas não vê qualquer relação entre o que faz e o objetivo pretendido pelo professor. Como pouco ou nada foi compartilhado, a comunidade se dispersa em ações individuais, segundo trilhas que não levam a qualquer destino.

A necessidade que tem o professor de formar uma comunidade coesa, capaz de se arregimentar em torno de um objetivo comum, existe não apenas em relação à sala de aula, mas também em relação a outras comunidades, das quais o professor pode participar. Incluem-se aí as associações de classe, os grupos de trabalho, SIGs (Special Interest Groups), etc. Algumas dessas comunidades poderiam incluir não só professores, mas também cientistas. Teríamos, assim, professores e cientistas na mesma comunidade, trocando idéias e experiências, trabalhando por objetivos comuns.

Haveria certamente a necessidade de uma divisão de trabalho, com o cuidado especial de evitar o surgimento de hierarquias indesejáveis (o cientista numa posição superior a do professor, por exemplo). A fusão entre o pensamento teórico e o prático poderia ser implementada, portanto, pela formação dessas comunidades des-hierarquizadas, em que professores relatassem suas experiências, incluindo o lado sofrido e prazeroso de seu trabalho e ouvissem dos cientistas suas angústias e esperanças, preocupados todos não apenas em relatar e descrever o mundo, mas também em modificálo. Os professores precisam talvez aprender que não há história sem mudança; 
os cientistas talvez não esquecer que a observação é sempre feita por um observador, a partir do contexto em que estiver inserido. Se cientista e professor têm uma visão diferente da realidade é porque estão olhando de lugares diferentes. Se o cientista desqualificar a perspectiva do professor estará prejudicando teoria. Se o professor rejeitar a perspectiva do cientista estará prejudicando a prática.

\section{Conclusão}

Embora desde muito se tenha defendido a necessidade de reduzir o abismo que existe entre a teoria e a prática, a realidade tem mostrado que esse abismo permanece o mesmo. O professor continua falando da perspectiva do pensamento prático e o cientista, por sua vez, da perspectiva do pensamento teórico. A transposição de um lugar para outro não é fácil; normalmente, é impossível. O que se percebe, porém, é que quando o cientista passa para o lugar do professor, começa a falar como professor, muitas vezes contrariando o que defende na teoria. Se o professor é criticado por não saber ensinar uma língua sem o uso do exercício, por exemplo, o cientista passa a agir da mesma maneira quando assume o lugar do professor. A sugestão defendida aqui para tentar diminuir esse abismo é, portanto, colocar o professor e o cientista numa mesma comunidade, criando um espaço em que possam trocar experiências e conhecimentos. Possivelmente o cientista precisa dar-se conta de que não existe aprendizagem de L2 sem a prática do exercício, e o professor precisa saber que só o exercício não basta. Essa necessidade de fusão entre o pensamento teórico e o prático, tendo como exemplo o uso do exercício, é a principal sugestão deste trabalho.

$\mathrm{Na}$ situação formal da sala de aula, em que é necessário simular a realidade que está lá fora no mundo, o recurso ao exercício é às vezes a única maneira de tentar desenvolver a competência lingüística. A aprendizagem é o mundo do faz-de-conta. Para os que preferem comparar a aquisição da segunda língua com a aquisição da primeira, podemos até dizer que se aprende uma língua brincando, como as crianças, fazendo de conta que são motoristas dirigindo caminhões, bombeiros apagando incêndios ou mães cuidando de bebês.

A defesa do uso do exercício é feita, no entanto, com algumas qualificações, incluindo a necessidade de (1) variar, (2) de contextualizar e de (3) ver o exercício como um meio para se chegar a um objetivo. Há exercícios e exercícios, como mesmo Wong e VanPatten (2003, p. 407) parecem admitir quando dizem que ao falar de drills estão se referindo aos exercícios mecânicos, 
sem considerar os drills significativos e comunicativos de Paulston (1976) ou os drills contextualizados de Omaggio Hadley (2001).

A variedade está não apenas no tipo de exercício usado (preenchimento de lacunas, múltipla escolha, inúmeros tipos de associação, solução de problemas, pergunta-resposta, etc.), mas também no processamento cognitivo e nas demandas afetivas que um determinado exercício pode acarretar. $\mathrm{O}$ simples preenchimento de uma lacuna pode exigir diferentes níveis de processamento cognitivo, do mais simples ao mais complexo, incluindo o conhecimento semântico, sintático e pragmático da língua.

A necessidade de contextualizar fica clara quando se vê o exercício como parte de um contexto maior, integrado a uma comunidade de aprendizes da língua, incluindo aí alunos, professores e os artefatos usados na sala de aula. $\mathrm{O}$ desempenho lingüístico é uma atividade complexa que envolve inúmeros processos e subprocessos. Às vezes alguns desses processos podem apresentar um desenvolvimento atrofiado em relação aos outros, provocando um desequilíbrio no desempenho do aluno (ex.: dificuldade em produzir determinados fonemas). Surge então a necessidade de se isolar um ou outro desses processos para dar a ele um tratamento localizado, corrigindo a deficiência e fazendo com que se integre adequadamente aos outros processos, recuperando o equilíbrio do sistema. Numa equipe de futebol, por exemplo, se um determinado jogador estiver com um problema no tornozelo, trabalhase especificamente o tornozelo, mas pensando mais no desempenho da equipe do que na saúde do jogador. É tão óbvia a relação entre o bem-estar do jogador e o desempenho da equipe que nem se cogita da necessidade ou não de dar um tratamento especial ao tornozelo afetado. Ninguém pensaria em tratar todos os tornozelos ao mesmo tempo porque um apresenta problemas.

Finalmente, o exercício será tão útil quanto for percebido como um meio necessário para atingir o objetivo, compartilhado tanto pelo professor como pelo aluno. Será prejudicial se visto apenas como um fim, principalmente se vier da imposição do professor que não consegue engajar o aluno no que acredita ser o melhor roteiro para a aprendizagem.

A conclusão é de que a tensão entre a teoria e a prática pode ser resolvida pela criação de uma comunidade maior, supradisciplinar, que reúna membros das duas comunidades; parte-se, portanto, do pressuposto de que, para haver entendimento, cientistas e professores devam pertencer à mesma comunidade. Um elo possível para a formação dessa comunidade é a produção de material didático, que pode funcionar como um elemento de ligação entre a teoria e a 
prática (KRAMSCH, 1995). A tentativa de fazer lingüistas aplicados e professores trabalharem juntos é provavelmente tão antiga como a própria Lingüística Aplicada. A novidade da proposta, no entanto, está em fazer com que falem dentro da mesma comunidade e, portanto, do mesmo lugar.

\section{Referências}

AUTHIER-REVUZ, Jacqueline. Heterogeneidade(s) enunciativa(s). Cadernos de Estudos Lingüisticos (19). Trad. Celene. M. Cruz e João Wanderley Geraldi. Campinas, 1990.

BROOKS, N. Language and language learning. New York:Harcourt, 1960.

GOODY, E. Learning and the division of labor. In: COY, M. (Ed.). Anthropological perspectives on apprenticeship. New York: SUNY Press, 1989. p. 233-257.

HALL, Stuart. A identidade cultural na pós-modernidade. Trad. Tomaz Tadeu da Silva e Guacira Lopes Louro. 8. ed. Rio de Janeiro: CP\&A, 2003

HAMMERLY, H. Fluency and accuracy: Toward balance in language teaching and learning. Clevedon: Multilingual Matters, 1991.

JORDAN, B. Cosmopolitical obstetrics: Some insights from the training of traditional midwives. Social Science and Medicine, v. 28, n. 9. p. 925-944. 1989.

KRAMSCH, Claire. The Applied Linguistic and the Foreign Language Teacher can they talk to each other? In: COOK, G.; SEIDLHOFER, B. (Ed.), Principle \& practice in applied linguistics: Studies in honor of H. G. Widdowson, 1995. p. 43-56.

KRASHEN, S. D. The case for narrow reading. TESOL Newsletter, v. 15, n. 6, p. 23, 1981.

KRASHEN, S. The case for narrow reading. Language Magazine, v. 3, n. 5 , p. 17-19, 2004.

KRASHEN, S. Principles and practice in second language acquisition. New York: Pergamon, 1982.

KRASHEN, S. The input hypothesis: uses and implications. London: Longman, 1985.

KRASHEN, S.D.; TERRELL, T.D. The Natural Approach. New York: Pergamon, 1983.

KUHN, T. S. A estrutura das revoluçôes científicas. Trad. Beatriz Viana e Nelson Boeira. 9. ed. São Paulo: Perspectiva, 2006 (1962). 
LAVE, J.; WENGER, E. Situated learning: Legitimate peripheral participation. Cambridge: Univesity Press, 1991.

LITTLEWOOD, W. Form and meaning in language teaching methodology. The Modern Language Journal, v. 64, n. 4, p. 441-445, 1980.

McCARTHY, M.; McCARTEN, J.; SANDIFORD, H. Touchstone. Cambridge: Cambridge University Press, 2005.

MOITA LOPES, L. P. da . Read, read, read. São Paulo: Ática, 1999.

NUNAN, D. Designing tasks for the communicative classroom. Cambridge: Cambridge University Press, 1992.

NUNAN, D. Second language teaching and learning. Boston: Heinle \& Heinle, 1999.

NUNAN, D. Expressions 2: Meaningful English communication (Workbook). Boston: Heinle \& Heinle/ Thomson Learning, 2001.

OMAGGIO HADLEY, A. Teaching language in context. Boston: Heinle \& Heinle, 2001.

PAULSTON, C. B. Teaching English as a second language: Techniques and procedures. Cambridge: Winthrop Publishers, 1976.

RICHARDS, J. C.; HULL, J.; PROCTOR, S. Interchange. 3. ed. Student's Book 1. Cambridge: University Press, 2005.

RIVERS, W. M. Teaching foreign language skills. Chicago: University of Chicago Press, 1981.

STERN, H. H. Fundamental concepts of language teaching. Oxford: Oxford University Press, 1991.

STEVICK, E. Memory, meaning, and method: A view of language teaching. Boston: Heinle \& Heinle, 1996.

VYGOTSKY, L. S. Pensamento e linguagem. Trad. Jefferson Luiz Camargo. São Paulo: Martins Fontes, 1993.

WINITZ, H. (ed.). The Comprehension Approach to Foreign Language Instruction. Rowley, MA: Newbury House, 1981.

WILLIS, J.; WILLIS, D. Collins COBUILD English course. London: Collins COBUILD, 1988.

WONG, W.; VANPATTEN, B. The evidence is IN: Drills are OUT. Foreign Language Annals, v. 36, n. 3, p. 403-423, 2003. 